\title{
Investigation of biomarker responses to depletion/repletion with vitamin $\mathbf{B}_{12}$
}

\author{
C. F. Hughes ${ }^{1}$, M. Ward ${ }^{1}$, L. Hoey ${ }^{1}$, A. Molloy ${ }^{2}$, K. Pentieva ${ }^{1}$, J. M. Scott ${ }^{2}$, F. Tracey ${ }^{3}$ \\ and H. McNulty \\ ${ }^{1}$ Northern Ireland Centre for Food and Health, University of Ulster, Coleraine BT52 1SA, UK, ${ }^{2}$ Trinity College, School of \\ Biochemistry and Immunology, Dublin, Ireland, and ${ }^{3}$ Causeway Hospital, Coleraine BT52 IHS, UK
}

Despite dietary intakes well above current recommendations, low biomarker status of vitamin $\mathrm{B}_{12}$ is a common problem in older adults, largely as a result of malabsorption of food-bound vitamin $\mathrm{B}_{12}$. This arises mainly from atrophic gastritis which leads to reduced gastric acid production (hypochlorhydria). Hydrochloric acid is essential for the absorption of food-bound vitamin $\mathrm{B}_{12}$, and thus vitamin $\mathrm{B}_{12}$ absorption is reduced in states of hypochlorhydria, although in theory free vitamin $\mathrm{B}_{12}$ (from supplements or fortified) should still be absorbed. Gastric acid suppressant medications, such as proton pump inhibitors (PPI) drugs induce hypochlorhydria and therefore a state similar to atrophic gastritis. The aim of the present study is to investigate the effect of hypochlorhydria on absorption of food-bound vitamin $\mathrm{B}_{12}$ and to determine whether low-dose supplemental vitamin $\mathrm{B}_{12}$ would overcome any vitamin $\mathrm{B}_{12}$ malabsorption. Forty-one healthy males, aged $18-45$, participated in a vitamin $\mathrm{B}_{12}$ depletion/repletion trial. During the depletion phase (week 0-6) all subjects were administered with a PPI (omeprazole, $20 \mathrm{mg} / \mathrm{d}$ ); after which they were randomised (by vitamin $\mathrm{B}_{12}$ status as measured by serum holotranscobalamin; holoTC; the metabolically active fraction of total circulating vitamin $\mathrm{B}_{12}$ ) into one of the two treatment groups to receive; omeprazole $(20 \mathrm{mg} / \mathrm{d})$ plus supplemental vitamin $B_{12}(10 \mu \mathrm{g} / \mathrm{d})$ or omeprazole $(20 \mathrm{mg} / \mathrm{d})$ plus placebo for the repletion phase of the study (week 7-12).
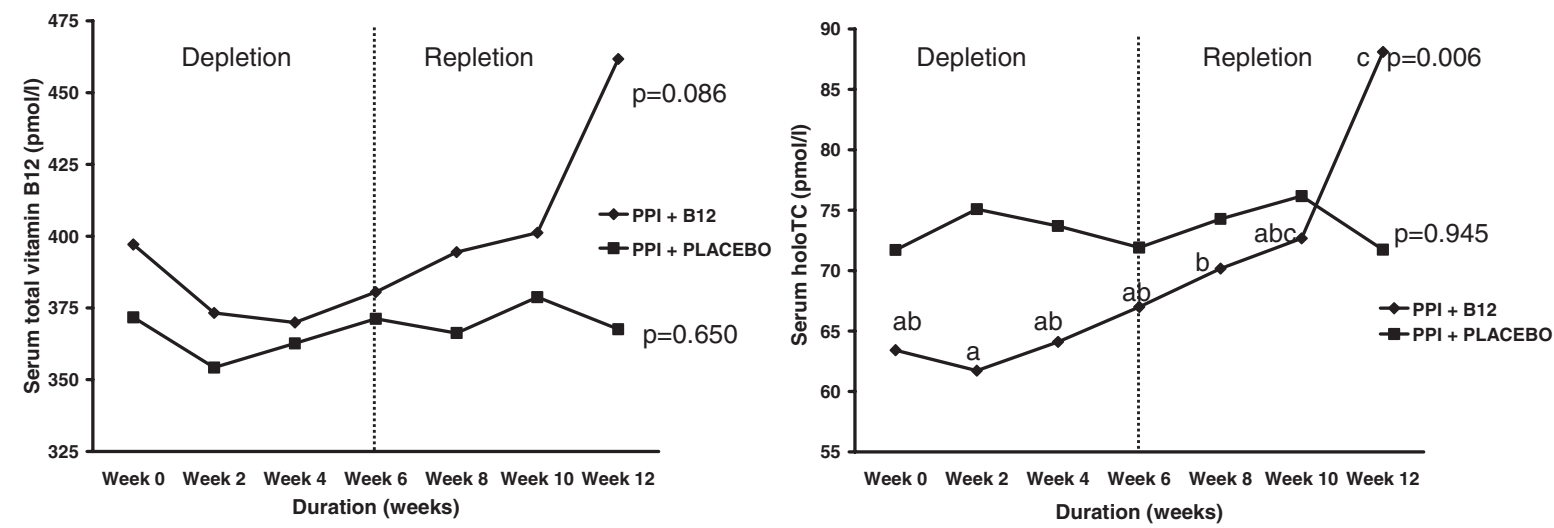

Fig. 1. Serum total $\mathrm{B} 12$ and holoTC responses to vitamin $\mathrm{B}_{12}$ depletion/repletion were compared by repeated measures ANOVA on log transformed data.

Contrary to expectations, no significant change in vitamin $\mathrm{B}_{12}$ status (as assessed by either total vitamin $\mathrm{B}_{12}$ or holoTC) was observed during the depletion phase of the study. During the repletion phase of the study, an increase in vitamin $\mathrm{B}_{12}$ status was observed in the treatment group, but this was significant $(P=0.006)$ only using the biomarker holoTC, with the response for total vitamin $\mathrm{B}_{12}$ failing to reach significance. In conclusion, these results supports the emerging view that holoTC (compared with the traditional biomarker of status, serum total vitamin $\mathrm{B}_{12}$ ) is a more sensitive biomarker in detecting small changes in vitamin $\mathrm{B}_{12}$ intake. Although the acute administration of PPI drugs did not significantly suppress vitamin $\mathrm{B}_{12}$, repletion with $10 \mu \mathrm{g} / \mathrm{d}$ of supplemental vitamin $\mathrm{B}_{12}$ was sufficient to significantly increase biomarker status within just 4 weeks. The consequence of long-term PPI therapy on vitamin $\mathrm{B}_{12}$ status is still to be determined. 